\title{
Growth Characteristics of Commercial Bumblebee Colonies in Open Field Conditions May Be Evidence for Their Invasion Potential
}

\author{
Ayhan Gosterit ${ }^{1, *}(\mathbb{D}$, Cengiz Erkan² \\ ${ }^{1}$ Isparta University of Applied Science, Faculty of Agriculture, Department of Animal Science, Isparta, Turkey \\ ${ }^{2}$ Van Yuzuncu YIl University, Faculty of Agriculture, Department of Animal Science, Van, Turkey
}

\section{Article History}

Received 16 May 2021

Accepted 06 June 2021

First Online 09 June 2021

\section{* Corresponding Author}

Tel.: +905337323985

E-mail: ayhangosterit@isparta.edu.tr

\section{Keywords}

Bombus terrestris

Commercial colony

Invasion potential

Sex production

\begin{abstract}
Colony parameters of laboratory reared Bombus terrestris L. colonies that placed to the field at the beginning of the social phase were observed. Founder queen of these field colonies was reared in commercially produced colonies. When the colony population reached about ten workers, they were transferred to the open field. No sugar syrup or pollen was supplied to colonies and was checked twice a week. The time of the first young queen and male observing, switch point, competition point and number of individuals produced in colonies were recorded during the colony controls. The first male and young queen emerging time after the end of the diapause were calculated as $85.00 \pm 3.21$ and $62.33 \pm 2.67$ days respectively. Competition point time was $40.50 \pm 1.32$ days, while switch point time was $16.00 \pm 3.70$ days in the social phase of colonies. Colonies produced $9.67 \pm 5.93$ young queens (gynes) and $39.50 \pm 14.20$ males during their life cycle. Results of this study revealed that commercially produced $B$. terrestris colonies can survive and produce sexuals in the native habitat.
\end{abstract}

\section{Introduction}

Bees which include more than twenty thousand species are the most valuable insect group and have about 8 or 9 families according to morphological traits (Donovan, 1980). Honeybees (Apis mellifera L.) are the most effective pollinator of natural flora due to their extensive rearing all over the world. Bumblebees, of which about 250 species have been reported, are other important pollinators of many flowering plants. In many countries, bumblebees are used as pollinators of many cultivated plants (Velthuis \& Van Doorn, 1996; Williams, 1998). Because their rearing is easy and the worker population is crowded than the other species, Bombus terrestris $\mathrm{L}$. is the most year-round reared, according to other bumblebee species. This species includes nine subspecies and is used mainly for tomato pollination in the greenhouse. They improve the quantity and quality of crops and decrease pollination labour costs. $B$. terrestris colonies which reared commercially are used in many countries, including some outside of their native range (Velthuis \& Van Doorn, 1996; Rasmont, Coppee, Michez, \& De Meulemeester, 2008).

Bumblebees are valuable and indispensable pollinators. However, it is also known that $B$. terrestris has an invasion potential into new areas where they are non-native. Early seasonal emergence, generalist or polylectic foraging strategies, high adaptability under adverse environmental conditions in a range of habitats, and their great phenological flexibility are the most critical invasive features. After its commercial introduction, it was determined that this species is invasive, can spread into new areas, and may disturb local ecology (Goulson, 2003; Dafni, Kevan, Gross, \& Goka, 2010). Competition with native organisms for nest sites and floral resources (Hingston \& McQuillan, 1998), 
the transportation of pathogens and parasites (Goka, Okabe, Yoneda, \& Niwa, 2001), hybridization with wild species (Ings, Ings, Chittka, \& Rasmont, 2010) and change of natural pollination systems (Hanley \& Goulson, 2003) are major problems that caused by the invasion and the increase in the population of introduced bumblebee in the new locations. A single colony can produce about a hundred new queens. These young queens could escape from greenhouses and found nests in the native habitat. Therefore, these environmental risks should be taken into account seriously (Gosterit \& Baskar, 2016).

Many studies have been carried out to determine the growth characteristics of commercial $B$. terrestris colonies under controlled conditions. Certainly, the results of the colony development patterns that have obtained from these studies belong to the colonies grown in the laboratory where the conditions in terms of climate and nutrients are optimum. However, it is expected that the colony growth characteristics, the number of queen and males produced, and the colony life span of these laboratory colonies are different from those colonies in field conditions where climatic conditions are variable and food resources are limited. In the field conditions, there are many factors that adversely affect the colony development such as rapid climatic changes, parasites, natural enemies, diseases and pests, agricultural and non-agricultural practices that limit nest areas and food resources. Despite the many characteristics of the $B$. terrestris species stated regarding the rapid spread, the local populations of this species live in a certain balance in accordance with the habitat and ecology they live in their natural range under the influence of these negative factors. It is estimated that this balance continues with a slow change for a long time unless there is an external intervention (Velthuis \& Van Doorn, 2006; Goka, 2010). Despite the possible risks to the natural ecosystem, the number of young queens and males produced in commercial $B$. terrestris colonies, whether these young queens and males produced in colonies can mate in the natural environment, whether they can establish a nest by surviving the diapause period, or the developmental characteristics of the nests in the open field are not fully known. This study, examining the development characteristics of commercial colonies under field conditions, was carried out to obtain scientific data on the spreading potential of $B$. terrestris.

\section{Materials and Methods}

Bombus terrestris colonies founded by queens reared in commercial colonies were used as bee material of the study. Standard rearing methods were applied for rear the colonies (Tuna \& Gosterit, 2017). According to the study aim, artificially hibernated queens were placed into starting boxes and allowed to found colonies under laboratory conditions $\left(27-28^{\circ} \mathrm{C}\right.$ and $\left.50 \% \mathrm{RH}\right)$. In this stage, fresh pollen and sugar solution (50 Brix degree) were used to fed queens and their colonies. When the population reached about 10 workers in the social phase, the colonies were transferred to rearing boxes and placed in the field without pollen and sugar solution. There was at least 25 meters distance between colonies placed on the field. The study was performed in Isparta (Turkey) between May and June, and the colonies were brought to the laboratory in the evenings twice a week and checked under red light. After the checking process, the colonies were taken back to their same location. Some growth characteristics were obtained for colonies: first male emergence time, first gyne emergence time, competition point (observation of some clues such as worker oviposition, oophagy, and egg-cup destruction), switch point (conversion time from worker production to queen and/or male production), and the total number of individuals (workers, males, and gynes) produced by each colony (Duchateau \& Velthuis, 1988). While the first male emergence time, the young queen emergence time and queen longevity were calculated from the date when the queens put into starting boxes, switch and competition point were calculated from the date when the first worker emerge (beginning of social phase). During the two months, the flowering plants which bumblebees forage and their flowering period were also determined. Minitab Statistical Software (Version 16.2.4) was used for data analysis and descriptive statistics of each colony growth traits were calculated.

\section{Results and Discussion}

Bombus terrestris colonies were placed in to the field at the beginning of the social phase without pollen and sugar solution and no extra feeding was provided to them until the end of their life cycle. Flowering plants used by bumblebees as nectar and pollen sources during the experiment and their flowering period are given in Table 1.

Table 1. Major flowering plants and their flowering period in study area

\begin{tabular}{|c|c|c|}
\hline Family & Species & Flowering period \\
\hline Rosaceae & $\begin{array}{l}\text { Malus communis } \\
\text { L. }\end{array}$ & 15 April - 5 May \\
\hline Ranunculaceae & Adonis spp. & 20 April - 20 May \\
\hline Brassicaceae & $\begin{array}{l}\text { Sinapis arvensis } \\
\text { L. }\end{array}$ & 25 April -15 June \\
\hline Fabaceae & $\begin{array}{l}\text { Onobrychis sativa } \\
\text { L. }\end{array}$ & 1 May - 25 May \\
\hline Rosaceae & $\begin{array}{l}\text { Rosa damascena } \\
\text { Mill. }\end{array}$ & 20 May - 20 June \\
\hline Apiaceae & Pimpinella spp. & 25 May - 15 June \\
\hline
\end{tabular}

Some development traits of $B$. terrestris colonies under field conditions are given in Table 2. Young queens and males are needed to establish a nest in native fauna in the next generation. Therefore, the most 
critical characteristics related to the invasion of bumblebees are the total number of males and young queens produced in the colonies. According to results, colonies produced $39.50 \pm 14.2$ young queens and

Table 2. Some growth characteristics of bumblebee colonies in open field conditions

\begin{tabular}{lcccc}
\hline Growth characteristic & $\mathrm{N}$ & Mean \pm SEM & Min. & Max. \\
\hline First male emergence time (days) & 7 & $85.00 \pm 3.21$ & 70.00 & 91.00 \\
First gyne emergence time (days) & 3 & $62.33 \pm 2.67$ & 57.00 & 65.00 \\
Switch point (days) & 7 & $16.00 \pm 3.70$ & 12.00 & 26.00 \\
Competition point (days) & 8 & $40.50 \pm 1.32$ & 37.00 & 44.00 \\
Total number of workers & 10 & $55.70 \pm 9.78$ & 26.00 & 110.00 \\
Total number of young queens & 6 & $39.50 \pm 14.20$ & 13.00 & 95.00 \\
Total number of males & 3 & $9.67 \pm 5.93$ & 1.00 & 21.00 \\
Queen longevity (days) & 10 & $89.90 \pm 4.59$ & 80.00 & 112.00 \\
\hline
\end{tabular}

$9.67 \pm 5.93$ males under field conditions.

In order to compare the results obtained in this study, the data obtained from the control groups of the other studies conducted by different researchers are given in Table 3. It is seen that fewer gynes and males are produced in colonies under field conditions compared to colonies that reared under laboratory conditions.

Table 3. Colony traits of captive $B$. terrestris colonies reported by different researchers

\begin{tabular}{lccc}
\hline & \multicolumn{2}{c}{ Reported literatures } \\
\cline { 2 - 4 } Colony traits & Tuna, 2016 & $\begin{array}{c}\text { Gosterit and Oytun } \\
\text { Cicek, 2017 }\end{array}$ & $\begin{array}{c}\text { Bulus, } 2019 \\
\text { Ozansoy Aksoy and Gosterit, } \\
2020\end{array}$ \\
\hline First male emergence time (days) & - & - & $74.64 \pm 3.01$ \\
Switch point (days) & $11.52 \pm 3.86$ & $25.03 \pm 1.98$ \\
Competition point (days) & $31.54 \pm 2.01$ & $26.55 \pm 1.12$ & $30.95 \pm 1.06$ \\
Total number of workers & $147.8 \pm 12.50$ & $108.73 \pm 6.51$ & $118.08 \pm 7.28$ \\
Total number of young queens & $42.61 \pm 5.33$ & $29.44 \pm 4.55$ & $108.40 \pm 10.50$ \\
Total number of males & $42.61 \pm 5.33$ & $34.94 \pm 7.57$ & $75.05 \pm 9.10$ \\
\hline
\end{tabular}

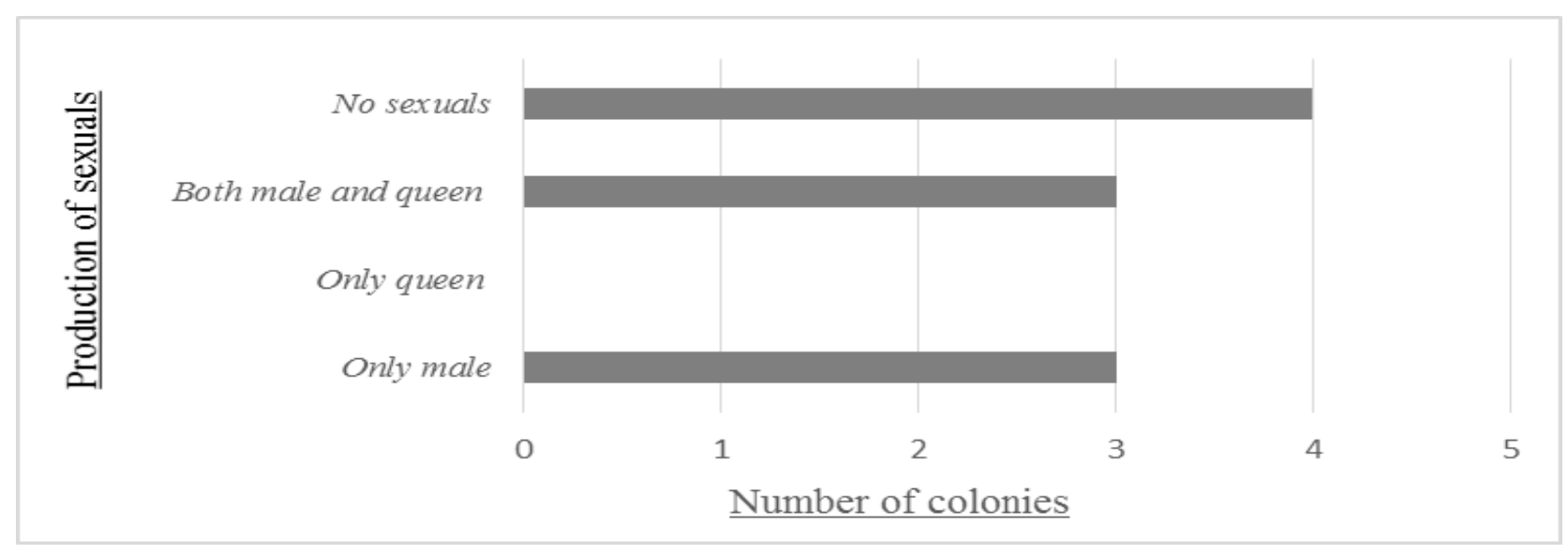

Figure 1. Male and young queen production success of colonies in field conditions 


\section{Conclusion}

The rearing of Bombus terrestris under controlled conditions is completely independent of nature. Both founder queens and colonies are kept under controlled environmental conditions and nutrition is provided to them unlimitedly. It is expected that colonies reared in the laboratory have some advantages over natural colonies in terms of their developmental characteristics and reproductive power due to optimum conditions in terms of nutrient source and physical environments. However, as before domestication, this species survived for years in the wild and still continues to live in nature. Our results showed that commercial bumblebee colonies can survive in natural fauna, maintain colony development and produce enough males and gynes to produce next generation or spread in nature. The results of the research have the quality to contribute scientifically to future studies about the invasive potential of bumblebees. In addition, it is also important to investigate some issues such as whether the young queens and males produced in colonies can mate, whether they can survive in diapause and found colony in following generations.

\section{References}

Bulus, I.Y. (2019). Comparison of colony foundation performances and colony development traits of young queens mated with males produced by queens and workers in Bombus terrestris (Master thesis). Isparta University of Applied Sciences, Institute of Graduate Education, Isparta, Turkey.

Dafni, A., Kevan, P., Gross, C.L., \& Goka, K. (2010). Bombus terrestris, pollinator, invasive, and pest: An assessment of problems associated with its widespread introductions for commercial purposes. Applied Entomology and Zoology, 45(1), 101-113.

Donovan, B. J. (1980). Interactions between native and introduced bees in New Zealand. New Zealand Journal of Ecology, 3, 104-116.

Duchateau M. J., \& Velthuis H. H. W. (1988). Development and reproductive strategies in Bombus terrestris colonies. Behaviour, 107(3-4), 186-207.

Goka, K., Okabe, K., Yoneda, M., \& Niwa, S. (2001). Bumblebee commercialization will cause worldwide migration of parasitic mites. Molecular Ecology, 10(8), 2095-2099.
Goka, K. (2010). Introduction to the special feature for ecological risk assessment of introduced bumblebees: Status of the European bumblebee, Bombus terrestris, in Japan as a beneficial pollinator and an invasive alien species. Applied Entomology and Zoology, 45(1), 1-6.

Gosterit, A., \& Baskar, V. C. (2016). Impacts of commercialization on the developmental characteristics of native Bombus terrestris (L.) colonies. Insectes Sociaux, 63(4), 609-614.

Gosterit, A., \& Oytun Çiçek, G. (2017). Effects of vitamin additive diets on colony foundation success in bumblebee, Bombus terrestris. Scientific papers, Series D., Animal Science, LX, 240-243.

Goulson, D. (2003). Effects of introduced bees on native ecosystems. Annual Review of Ecology, Evolution and Systematics, 34(1), 1-26.

Hanley, M. E., \& Goulson, D. (2003). Introduced weeds pollinated by introduced bees: Cause or effect? Weed Biology and Management, 3(4), 204-212.

Hingston, A. B., \& McQuillan, P. B. (1998). Does the recently introduced bumblebee Bombus terrestris (Apidae) threaten Australian ecosystems? Australian Journal of Zoology, 23(6), 539-549.

Ings, T. C., Ings, N. L., Chittka, L., \& Rasmont, P. (2010). A failed invasion? Commercially introduced pollinators in Southern France. Apidologie, 41(1), 1-13.

Ozansoy Aksoy, A., \& Gösterit, A. (2020). How does the constricted nest area affect colony dynamics in bumblebee. Süleyman Demirel University, Journal of Faculty of Agriculture, 15(2), 138-142.

Rasmont, P., Coppee, A., Michez, D., \& De Meulemeester, T. (2008). An overview of the Bombus terrestris (L.1758) subspecies (Hymenoptera:Apidae). Annals de la Societe Entomologique de France, 44, 43-250.

Tuna, B. (2016). Effects of pre-diapause feeding on diapause performance and colony development in Bombus terrestris queens (Master thesis). Süleyman Demirel University, Graduate School of Applied and Natural Sciences, Isparta, Turkey.

Tuna, B., \& Gosterit, A. 2017. Effects of pre-diapause feeding on colony foundation success in Bombus terrestris queens. Süleyman Demirel University, Journal of Faculty of Agriculture, 12(1), 49-55.

Velthuis, H. H. W., \& Van Doorn, A. (2006). A century of advances in bumble bee domestication and the economic and environmental aspects of its commercialization for pollination. Apidologie, 37(4), 421-451.

Williams, P. H. (1998). An annotated checklist of bumblebees with an analysis of patterns of description. Bulletin of the Natural History Museum: Entomology Series, 67, 79152. 